\title{
Splendid Isolation: The Curious History of South American Mammals, by George Gaylord Simpson. Yale University Press, £11.
}

Of all the continents South America in particular lends itself to an attempt to provide a concise but comprehensive historical account of its mammal fauna. Its isolation through most of the Tertiary period, the 'age of mammals', was only a little less complete than that of Australia, but its fossil record is enormously more comprehensive, with an almost continuous sequence from the late Cretaceous, when a few fragments demonstrate the existence of marsupials and primitive ungulates, to the Pleistocene and post-Pleistocene when the distinctive 'megafauna' of giant sloths, glyptodons, sabre-toothed cats, elephants etc. finally disappeared from the scene. However, continuity of a fossil record is a relative concept and even the best needs a skilled practitioner to make any sense of a sequence whose successive elements may not only be separated by a few million years but by several thousand miles, and may be represented, through the fortuitous nature of fossilisation, by small random samples of the species actually present and by equally small, erratic samples of their bones or teeth.

George Gaylord Simpson is a guide who inspires confidence. He has been an active student of the fossil mammals of South America, in the field and in museums, for fifty-five years and it is very pleasing that he has condensed his vast experience into such a digestible form. It is basically a chronological account, documenting the arrival and radiation of the strange edentates, ungulates, caviomorph rodents and primates and their relatively recent interaction with invaders from North America as the island continent rejoined its northern neighbour within the last two million years or so.

To some extent the book falls between two stools - it is written in narrative form rather than as a reference work, but the detailed discussion of unfamiliar groups can be rather tedious for those without the existing framework of knowledge on which to hang the details (in spite of the author's statement in the preface that he has 'not assumed any previous technical or detailed knowledge of the subject'). There are intermittent glimpses of the fossil sites and of the personalities of the palaeontologists who explored them, but in a subject where interpretation has been a distinctly subjective matter one might have hoped for a little more flesh to clothe the bones of the palaeontologists if not of the fossil mammals themselves.

GORDON B. CORBET

Hawaiian Reptiles and Amphibians, by Sean McKeown. Oriental Publishing Co., Honolulu, $\$ 3.50$

\section{Vertebrates of Florida, by Henry M. Stevenson. Florida University Press, $\$ 35$.}

Florida and Hawaii are two states of the USA which share an ongoing problem: introduced species. Even five years ago Florida's vertebrates included a dozen species of reptiles and amphibians, 25 birds and 10 mammals which were the result of escapes or liberations, among them such exotics as rhesus monkey, spectacled caiman and budgerigar. But interesting as Florida's native fauna is (or was), it cannot match that of Hawaii in terms of endemic species; neither can it match it for introductions and extinctions.

Only four of Hawaii's 22 species of reptiles and amphibians can be considered native: one sea snake and three marine turtles. The rest, which include poison arrow frogs, bullfrogs, chameleon, gekkos, skinks and snakes, have been brought by man. In fact introductions have been going on so long that some, such as the Eurasian toad Bufo bufo and the black spotted frog Rana nigromaculata, have not been recorded since the war. The history of species such as the giant toad Bufo marinus, introduced in 1932 to control sugar cane beetles - and of course ran amok - is almost too well known to need repeating. But some species, including four geckos and three skinks, were probably 